\title{
The Influence of Timing of Coronary Angiography on Acute Kidney Injury in Out-of-Hospital Cardiac Arrest Patients: A Retrospective Cohort Study.
}

Gladys Nathalia Janssens

Amsterdam UMC - Locatie VUMC: Amsterdam UMC Locatie VUmc https://orcid.org/0000-0002-99954300

Joost Daemen

Erasmus Medical Centre: Erasmus MC

Jorrit S. Lemkes

Amsterdam UMC - VUMC location: Amsterdam UMC Locatie VUmc

Eva M. Spoormans

Amsterdam UMC - Locatie VUMC: Amsterdam UMC Locatie VUmc

Dieuwertje Janssen

Amsterdam UMC - Locatie VUMC: Amsterdam UMC Locatie VUmc

Corstiaan A. den Uil

Erasmus Medical Centre: Erasmus MC

Lucia S.D. Jewbali

Erasmus Medical Centre: Erasmus MC

Ton A.C.M. Heestermans

Noordwest Ziekenhuisgroep

Victor A.W.M. Umans

Noordwest Ziekenhuisgroep

Frank R. Halfwerk

Medisch Spectrum Twente

Albertus Beishuizen

Medisch Spectrum Twente

Joris Nas

UMCN: Radboudumc

Judith Bonnes

UMCN: Radboudumc

Peter M. van de Ven

Amsterdam UMC - Locatie VUMC: Amsterdam UMC Locatie VUmc

Albert C. van Rossum

Amsterdam UMC - Locatie VUMC: Amsterdam UMC Locatie VUmc 


\section{Paul W.G. Elbers}

Amsterdam UMC - Locatie VUMC: Amsterdam UMC Locatie VUmc

Niels van Royen ( $\square$ Niels.vanRoyen@radboudumc.nl )

Amsterdam UMC - Locatie VUMC: Amsterdam UMC Locatie VUmc

\section{Research}

Keywords: Acute kidney injury, out-of-hospital cardiac arrest, coronary angiography, creatinine, risk factors, reperfusion injury.

Posted Date: September 13th, 2021

DOl: https://doi.org/10.21203/rs.3.rs-876399/v1

License: (c) (i) This work is licensed under a Creative Commons Attribution 4.0 International License. Read Full License

Version of Record: A version of this preprint was published at Annals of Intensive Care on February 11th, 2022. See the published version at https://doi.org/10.1186/s13613-022-00987-w. 


\section{Abstract}

Background: Acute kidney injury (AKI) is a frequent complication in cardiac arrest survivors and associated with adverse outcome. It remains unclear whether the incidence of AKI increases after the post-cardiac arrest administration of contrast for coronary angiography and whether this depends on timing of contrast administration. Aim of this study was to investigate whether early angiography is associated with increased development of AKI compared to deferred angiography in out-of-hospital cardiac arrest (OHCA) survivors.

Methods: In this retrospective multicenter cohort study we investigated whether early angiography (within $2 \mathrm{~h}$ ) after OHCA was non-inferior to delayed/no angiography regarding the development of AKI. We used an absolute difference of $5 \%$ as the non-inferiority margin. Primary non-inferiority analysis was done by calculating the risk difference with its $90 \%$ confidence interval $(\mathrm{Cl})$ using a generalized linear model for a binary outcome and the identity link-function. As a sensitivity analysis we repeated the primary analysis using propensity score matching.

Results: A total of 2151 patients were included in the study from 2009 until 2018, of which 1062 patients were treated with early coronary angiography and 1089 patients with delayed or no angiography. The proportion that developed $\mathrm{AKI}$ after OHCA was $17.8 \%$ in the early angiography group and $21.5 \%$ in the deferred angiography group. Risk difference was $-3.7 \%$ with $90 \% \mathrm{Cl}$ ranging from $-6.7 \%$ to $-0.7 \%$, indicating non-inferiority of early angiography at the prespecified margin of $5 \%$. As sensitivity analysis we repeated the primary analysis using propensity score matching, which accordingly showed non-inferiority of early angiography. A multivariable model was built to identify predictors of acute kidney injury. The factors time to return of spontaneous circulation (odds ratio [OR] 1.10, 95\% Cl 1.05-1.15, p<0.001) and baseline creatinine (OR 1.05, 95\% $\mathrm{Cl} 1.03-1.07, \mathrm{p}<0.001)$ were found to be independently associated with the development of AKI.

Conclusions: Although AKI occurred in approximately $20 \%$ of OHCA patients, we found that early angiography had an equal AKI incidence as a delayed or no angiography strategy. The present results implicate that it is safe to perform early coronary angiography with respect to the risk of developing AKI after OHCA.

\section{Background}

In patients who achieve return of spontaneous circulation (ROSC) after out-of-hospital cardiac arrest (OHCA), the subsequent high morbidity and mortality are mostly due to neurologic injury, systemic ischemia-reperfusion injury and multi-organ dysfunction. Although post-resuscitation treatment for OHCA patients has improved over the years, prognosis for these patients remains poor. Several key predictors for survival after the event have been identified, and include witnessed arrest, early initiation of cardiopulmonary resuscitation, time to ROSC and acute kidney injury (AKI)(1). AKI is often observed after cardiac arrest and associated with adverse outcome $(2-5)$. Whether cardiac arrest patients develops AKI 
depends on several factors such as age, comorbidity, prior renal insufficiency and time to $\operatorname{ROSC}(6,7)$. Other risk factors include diabetes and hypertension $(6,7)$. Congestive heart failure, hypotension after cardiac arrest, female sex and usage of an intra-aortic balloon pump are also associated with increased incidence of $\mathrm{AKI}(8)$.

Another factor that might influence the development of AKI after cardiac arrest is the usage of iodinated contrast during imaging techniques such as coronary angiography(9). Currently it is unclear whether the incidence of AKI increases after the administration of iodinated contrast agents post-cardiac arrest and whether the timing of administration influences the development of AKI.

\section{Methods}

\section{Study design}

Using data from 19 of 23 Dutch cardiac intervention centers, a retrospective cohort study of patients resuscitated after OHCA between January 2009 and July 2018 was conducted. The study protocol was approved by the IRB of the VU University Medical Center and ethics approval was obtained by the medical ethics committee of the VU University Medical Center, Amsterdam, the Netherlands with approval number 2017.398. Informed consent was waived, as it was not achievable to obtain this from all patients of the large retrospective study cohort.

\section{Patients}

Patients admitted to the participating hospitals and coded with OHCA were screened for inclusion in the study. Patients were eligible for this study if they were eighteen years or older and had ROSC. Patients were excluded when they had no creatinine values until day 3 or if time from OHCA to angiography was unknown. Furthermore patients who died within $48 \mathrm{~h}$ after OHCA were excluded as this time window is necessary to assess whether AKI devellops.

\section{Treatment}

Post-resuscitation care was at the discretion of the clinicians responsible for the patient. According to international guidelines, in patients with persistent ST-elevation on the electrocardiogram emergency angiography and subsequent percutaneous coronary intervention $(\mathrm{PCl})$ was performed $(10,11)$. In patients without ST-elevation, angiography was either performed immediately or delayed(12,13). Patients receiving angiography within $2 \mathrm{~h}$ after OHCA were considered to have had early angiography.

\section{Data collection and outcomes}

Patient data was anonymized by assigning a random record number to each patient included in the study. Information regarding demographics, pre-hospital settings, status at admission, medical history, clinical and laboratory data (e.g. renal function, blood cell count, $\mathrm{pH}$, lactate) was collected from patient records. Also, available renal function tests at 1 year were collected. 
The primary endpoint of this study was the AKI incidence in patients receiving early angiography compared to patients with delayed or no angiography. AKI was defined according to Acute Kidney Injury Network (AKIN) criteria, ranging from stage 1 to 3 , with higher stages indicating more severe renal failure (See Supplemental Data)(14). We used the creatinine level at admission as baseline value. Daily serum creatinine was measured in local laboratories. The highest creatinine value within $48 \mathrm{~h}$ was used to calculate the AKIN category.

\section{Statistical analysis}

Minimal sample size was calculated for the expected incidence and difference of AKI between the early and deferred angiography group. The previous study by Petek et al. showed an overall incidence of AKI of $15 \%$ with a (non-significant) difference of $4.3 \%$ between early and non-early angiography(15). With an expected incidence of AKI of $20 \%$ in both groups and a non-inferiority margin of $5 \%$ for the risk difference, we would need 792 patients per treatment group to have $80 \%$ power assuming non-inferiority testing at a one-sided significance level of $5 \%$.

Primary non-inferiority analysis was done by calculating the risk difference with its $90 \%$ confidence interval $(\mathrm{Cl})$ using a generalized linear model for a binary outcome and the identity link-function. As a sensitivity analysis we repeated the primary analysis using propensity score matching using six baseline characteristics.

Continuous variables were compared using the independent-samples t-test for normally distributed data and summarized by mean and standard deviation. Skewed data were compared using the Mann-Whitney $\mathrm{U}$ test and summarized by median and interquartile range. Categorical variables were compared using the chi-square test or Fisher's exact test in case of low expected cell counts and summarized by counts and percentages.

Univariable and multivariable logistic regression analysis was used to identify predictors of AKI. Statistical significance was assumed when $p$-values for two-sided testing were $<0.05$, except for the primary non-inferiority hypothesis for which a $p$-value for one-sided $<0.05$ was considered significant. Further details of the statistical analysis are provided in the Supplemental Data.

\section{Results}

\section{Patients}

A total of 2151 OHCA patients were included in this study. Of these patients 1062 were treated with early angiography and 1089 with delayed or no angiography. Most patients were male (70.4\%)(Table 1). Patients in the deferred angiography group were slightly older than the patients in the early angiography group $(63.6 \pm 14.9$ vs. $62.1 \pm 12.4, p=0.01)$ and had more often a history of myocardial infarction $(24.6 \%$ vs. $20.6 \%, p=0.03$ ). In both groups ventricular tachycardia/ventricular fibrillation was the most common arrest rhythm, but more frequently in the early angiography group ( $93.9 \% \mathrm{vs.} 78.2 \%, p<0.001)$. Overall, the median time to ROSC was 15 (10-22) minutes. Patients in the deferred angiography group were more frequently comatose on admission $(91.7 \%$ vs. $86.3 \%, p=0.001)$, while patients in the early angiography 
group more often had a ST-elevation myocardial infarction (STEMI)(10) upon medical presentation $(42.5 \%$ vs. $13.0 \%, p<0.001)$. In the deferred angiography group more patients had chronic kidney disease $(8.2 \%$ vs. $3.0 \%, p<0.001)$ and accordingly their median creatinine values at admission were higher than in the early angiography group (Table 1, Fig. 1, Supplemental Table 1). 
Table 1

Baseline characteristics

\begin{tabular}{|c|c|c|c|c|}
\hline Characteristic & $\begin{array}{l}\text { All patients } \\
(\mathrm{N}=2151)\end{array}$ & $\begin{array}{l}\text { Early CAG } \\
(\mathrm{N}=1062)\end{array}$ & $\begin{array}{l}\text { Deferred/no } \\
\text { CAG } \\
(\mathrm{N}=1089)\end{array}$ & $\begin{array}{l}\text { p- } \\
\text { value }\end{array}$ \\
\hline \multicolumn{5}{|l|}{ Patient characteristics } \\
\hline Male sex & $1514(70.4)$ & $741(69.8)$ & 773 (71.0) & 0.54 \\
\hline Age in years & $63 \pm 14$ & $62 \pm 12$ & $64 \pm 15$ & 0.013 \\
\hline Hypertension & $\begin{array}{l}765 / 1860 \\
(41.1)\end{array}$ & $375 / 899(41.7)$ & $390 / 961(40.6)$ & 0.62 \\
\hline Diabetes mellitus & $\begin{array}{l}327 / 2023 \\
(16.2)\end{array}$ & $\begin{array}{l}159 / 1029 \\
(15.5)\end{array}$ & 168/994 (16.9) & 0.38 \\
\hline Hypercholesterolemia & $\begin{array}{l}272 / 1116 \\
(24.4)\end{array}$ & $122 / 496(24.6)$ & $150 / 620(24.2)$ & 0.77 \\
\hline Previous cardiac arrest & $21 / 902(2.3)$ & $9 / 530(1.7)$ & 12/372 (3.2) & 0.13 \\
\hline Previous myocardial infarction & $\begin{array}{l}449 / 1991 \\
(22.6)\end{array}$ & $\begin{array}{l}209 / 1017 \\
(20.6)\end{array}$ & $240 / 974(24.6)$ & 0.03 \\
\hline Previous CVA or TIA & $41 / 651(6.3)$ & 24/336 (7.1) & $17 / 315(5.4)$ & 0.42 \\
\hline Chronic kidney disease & $56 / 1029(5.4)$ & 16/541 (3.0) & $40 / 488(8.2)$ & $\begin{array}{l}< \\
0.001\end{array}$ \\
\hline $\begin{array}{l}\text { Previous renal replacement } \\
\text { therapy }\end{array}$ & $12 / 908(1.3)$ & $5 / 533(0.9)$ & 7/375 (1.9) & 0.25 \\
\hline \multicolumn{5}{|l|}{ Pre-hospital characteristics } \\
\hline Arrest witnessed & $\begin{array}{l}909 / 1123 \\
(80.9)\end{array}$ & $465 / 565(82.3)$ & 444/558 (79.6) & 0.24 \\
\hline \multicolumn{5}{|l|}{ First rhythm } \\
\hline VF/VT & $\begin{array}{l}945 / 1094 \\
(86.4)\end{array}$ & $537 / 572(93.9)$ & $408 / 522(78.2)$ & \\
\hline PEA & 43/1094 (3.9) & $10 / 572(1.7)$ & $33 / 522(6.3)$ & \\
\hline Asystole & $106 / 1094(9.7)$ & $25 / 572(4.4)$ & $81 / 522(15.5)$ & \\
\hline
\end{tabular}

All data are expressed in numbers and percentages (\%). Plus-minus $( \pm)$ values are classified as mean and standard deviation (SD). Brackets are classified as median and interquartile ranges (IQR).

CAG denotes coronary angiography, CVA cerebrovascular accident, TIA transient ischemic attack, VF ventricular fibrillation, VT ventricular tachycardia, PEA pulseless electrical activity, BLS basic life support, ROSC return of spontaneous circulation, STEMI ST-segment elevation myocardial infarction, CT computed tomography, CRP C-reactive protein. 


\begin{tabular}{|c|c|c|c|c|}
\hline Characteristic & $\begin{array}{l}\text { All patients } \\
(\mathrm{N}=2151)\end{array}$ & $\begin{array}{l}\text { Early CAG } \\
(\mathrm{N}=1062)\end{array}$ & $\begin{array}{l}\text { Deferred/no } \\
\text { CAG } \\
(\mathrm{N}=1089)\end{array}$ & $\begin{array}{l}\text { p- } \\
\text { value }\end{array}$ \\
\hline $\begin{array}{l}\text { Time from arrest to BLS in } \\
\text { minutes }\end{array}$ & $3[1-5]$ & $3[1-5]$ & $3[1-5]$ & 0.24 \\
\hline $\begin{array}{l}\text { Time from arrest to ROSC in } \\
\text { minutes }\end{array}$ & 15 [10-22] & 15 [10-22] & 15 [10-22] & 0.54 \\
\hline \multicolumn{5}{|c|}{ Characteristics on hospital arrival } \\
\hline Glasgow coma scale $<8$ & $\begin{array}{l}1248 / 1401 \\
(89.1)\end{array}$ & $592 / 686(86.3)$ & $656 / 715(91.7)$ & 0.001 \\
\hline Signs of STEMI on ECG & $\begin{array}{l}496 / 1788 \\
(27.7)\end{array}$ & $380 / 894(42.5)$ & $116 / 894(13.0)$ & $\begin{array}{l}< \\
0.001\end{array}$ \\
\hline CT scan performed & $289 / 672(43.0)$ & $189 / 348(54.3)$ & $100 / 324(30.9)$ & $<.001$ \\
\hline \multicolumn{5}{|l|}{$\begin{array}{l}\text { Laboratory values upon } \\
\text { admission }\end{array}$} \\
\hline $\mathrm{pH}$ & $\begin{array}{l}7.24[7.12- \\
7.31]\end{array}$ & $\begin{array}{l}7.24[7.15- \\
7.31]\end{array}$ & $\begin{array}{l}7.24[7.11- \\
7.31]\end{array}$ & 0.41 \\
\hline Lactate, $\mathrm{mmol} / \mathrm{L}$ & $5.5[3.4-8.6]$ & $5.4[3.4-8.3]$ & $5.8[3.4-8.9]$ & 0.11 \\
\hline Hemoglobin, mmol/L & $8.5 \pm 1.2$ & $8.6 \pm 1.1$ & $8.4 \pm 1.3$ & 0.01 \\
\hline Hematocrit & $0.40 \pm 0.05$ & $0.41 \pm 0.05$ & $0.40 \pm 0.06$ & 0.02 \\
\hline Leukocytes, $\cdot 10^{9} / \mathrm{L}$ & $12.5[9.8-16.7]$ & $\begin{array}{l}12.5[10.0- \\
16.9]\end{array}$ & $12.4[9.6-16.2]$ & 0.35 \\
\hline CRP, mg/L & $5[3-18]$ & $4[3-16]$ & $5[3-20]$ & 0.18 \\
\hline Creatinine, $\mu \mathrm{mol} / \mathrm{L}$ & 97 [81-115] & $95[81-112]$ & 99 [81-119] & 0.001 \\
\hline Creatinine $>130 \mu \mathrm{mol} / \mathrm{L}$ & $\begin{array}{l}304 / 2129 \\
(14.3)\end{array}$ & $\begin{array}{l}122 / 1053 \\
(11.6)\end{array}$ & $\begin{array}{l}182 / 1076 \\
(16.9)\end{array}$ & $<.001$ \\
\hline \multicolumn{5}{|c|}{$\begin{array}{l}\text { All data are expressed in numbers and percentages (\%). Plus-minus ( } \pm \text { ) values are classified as mean } \\
\text { and standard deviation (SD). Brackets are classified as median and interquartile ranges (IQR). }\end{array}$} \\
\hline \multicolumn{5}{|c|}{$\begin{array}{l}\text { CAG denotes coronary angiography, CVA cerebrovascular accident, TIA transient ischemic attack, VF } \\
\text { ventricular fibrillation, VT ventricular tachycardia, PEA pulseless electrical activity, BLS basic life } \\
\text { support, ROSC return of spontaneous circulation, STEMI ST-segment elevation myocardial infarction, } \\
\text { CT computed tomography, CRP C-reactive protein. }\end{array}$} \\
\hline
\end{tabular}

Treatments 
Angiography was performed in $52.8 \%$ of patients with deferred angiography (Table 2). Median time to angiography was 75 (52-93) minutes in the early angiography group and 1003 (151-8795) minutes in the delayed angiography group ( $\mathrm{p}<0.001)$. PCl was performed in $82.7 \%$ of the patients in the early angiography group and $36.8 \%$ in the deferred angiography group $(p<0.001)$. Furthermore, patients in the early angiography group more frequently underwent a computerized tomography scan than patients in the deferred angiography group $(54.3 \%$ vs. $30.9 \%, p<0.001)$. Approximately $80 \%$ of patients in both groups were treated with targeted temperature management. 
Table 2

In-hospital procedures, treatments and characteristics

\begin{tabular}{|c|c|c|c|}
\hline Variable & $\begin{array}{l}\text { Early CAG group } \\
(\mathrm{N}=1062)\end{array}$ & $\begin{array}{l}\text { Deferred CAG/no CAG group } \\
(\mathrm{N}=1089)\end{array}$ & p-value \\
\hline Targeted temperature management & 624/783 (79.7) & $523 / 636(82.2)$ & 0.23 \\
\hline Hypotension & 200/504 (39.7) & 230/601 (38.3) & 0.63 \\
\hline Use of inotropic or vasopressors & 297/471 (63.1) & $365 / 598(61.0)$ & 0.50 \\
\hline Use of intra-aortic balloon pump & 79/915 (8.6) & 32/909 (3.5) & $<0.001$ \\
\hline Heart failure $<45 \%$ & 182/461 (39.5) & $122 / 281(43.4)$ & 0.29 \\
\hline Need for renal replacement therapy & $30 / 774(3.9)$ & $38 / 628(6.1)$ & 0.06 \\
\hline Major bleeding ${ }^{a}$ & 12/321 (3.7) & $17 / 312(5.4)$ & 0.30 \\
\hline CAG performed & $1062(100.0)$ & $575(52.8)$ & $<0.001$ \\
\hline $\mathrm{PCl}$ performed & 191/231 (82.7) & $114 / 310(36.8)$ & $<0.001$ \\
\hline CABG & $7 / 272(2.6)$ & $9 / 345(2.6)$ & 0.98 \\
\hline \multicolumn{4}{|l|}{ Laboratory values } \\
\hline Lowest pH & $7.21[7.10-7.26]$ & $7.18[7.03-7.26]$ & 0.01 \\
\hline Peak lactate, $\mathrm{mmol} / \mathrm{L}$ & $5.4[3.4-8.8]$ & $5.5[3.2-8.9]$ & 0.78 \\
\hline Peak CRP, mg/L & 108 [37-206] & $130[71-205]$ & 0.02 \\
\hline Peak leukocytes, $\cdot 10^{9} / \mathrm{L}$ & $18.1[14.1-23.8]$ & $18.2[14.1-23.3]$ & 0.84 \\
\hline Peak CK, U/L & $1491[634-4262]$ & 845 [305-2378] & $<0.001$ \\
\hline Survival until hospital discharge & $406 / 588(69.0)$ & $375 / 574(65.3)$ & 0.18 \\
\hline \multicolumn{4}{|c|}{$\begin{array}{l}\text { a Major bleeding was scored using BARC classification scores } \geq 3 \text {, ranging from bleeding that is not } \\
\text { actionable to fatal bleedings. }\end{array}$} \\
\hline \multicolumn{4}{|c|}{$\begin{array}{l}\text { All data are expressed in numbers and percentages (\%). Brackets are classified as median and } \\
\text { interquartile ranges (IQR). }\end{array}$} \\
\hline
\end{tabular}

\section{Acute kidney injury}

In the early angiography group $17.8 \%$ and in the deferred angiography group $21.6 \%$ developed $\mathrm{AKI}$ after OHCA. Risk difference was $-3.7 \%$ with $90 \% \mathrm{Cl}-6.7-0.7 \%$, indicating non-inferiority of early angiography in terms of AKI after OHCA. Also after propensity score matching non-inferiority was concluded with risk difference $-3.8 \%$ and $90 \% \mathrm{Cl}-6.8-0.7 \%$ (Supplemental Table 2). Most frequently patients developed AKIN 
stage $1(10.4 \%$ in the early angiography vs. $12.1 \%$ in the deferred angiography group, $p=0.25)$ (Fig. 2 ). Overall, $3.4 \%$ of patients developed AKI stage 2 and $5.0 \%$ AKI stage 3 , which did not differ between the groups. Accordingly, propensity matched analysis showed that patients undergoing early angiography did not develop more AKI and the distribution in classifications did not differ (Supplemental Table 2). Within the deferred angiography group, patients without angiography developed more AKI than patients undergoing late angiography ( $24.4 \%$ vs. $18.8 \%, p=0.037)$. RRT was not performed more frequently in the early angiography group ( $3.9 \%$ vs. $6.1 \%, p=0.06)$ (Table 2$)$. Creatinine at day 3 was persistently higher in the deferred angiography group compared to patients with early angiography $(84$ [67-126] $\mu \mathrm{mol} / \mathrm{L}$ vs. 79 [65-101] $\mu \mathrm{mol} / \mathrm{L}, \mathrm{p}<0.001$ )(Fig. 1, Supplemental Table 1). Creatinine before discharge and available creatinine one month and one year after discharge were not different between the groups.

Patients who developed AKI were characterized by older age, a greater proportion of diabetes, a lower incidence of witnessed arrest and shockable rhythm, a longer duration from arrest to basic life support and ROSC, more frequent hypotension, heart failure and treatment with inotropics or vasopressors and targeted temperature management (Supplemental Table 3).

Logistic regression analysis was performed to identify predictors of AKI (Table 3). Time to ROSC and baseline creatinine were identified as independent predictors for AKI. After correction for risk factors, early coronary angiography and amount of contrast were not found to be associated with occurrence of AKI. 
Table 3

Univariable and multivariable analysis on predictors of acute kidney injury

\begin{tabular}{|c|c|c|c|c|}
\hline \multicolumn{3}{|l|}{ Univariable analysis } & \multicolumn{2}{|c|}{ Multivariable analysis* } \\
\hline Predictor and covariates & $\begin{array}{l}\text { Odds ratio (95\% } \\
\text { Cl) }\end{array}$ & $\begin{array}{l}\mathrm{p}- \\
\text { value }\end{array}$ & $\begin{array}{l}\text { Odds ratio (95\% } \\
\text { Cl) }\end{array}$ & $\begin{array}{l}\text { p- } \\
\text { value }\end{array}$ \\
\hline Early coronary angiography & $0.79(0.63-1.00)$ & 0.045 & & \\
\hline Sex (reference $=$ female) & $1.07(0.83-1.37)$ & 0.62 & & \\
\hline Age (per year) & $1.01(1.00-1.02)$ & 0.038 & & \\
\hline Diabetes mellitus & $1.39(1.03-1.86)$ & 0.029 & & \\
\hline Hypertension & $0.97(0.76-1.24)$ & 0.80 & & \\
\hline Arrest witnessed & $1.61(1.11-2.33)$ & 0.011 & & \\
\hline Time from arrest to BLS (per minute) & $1.08(1.04-1.12)$ & $\dot{0} 001$ & & \\
\hline $\begin{array}{l}\text { Time from arrest to ROSC (per } \\
\text { minute) }\end{array}$ & $1.03(1.02-1.04)$ & $<0.001$ & $1.10(1.05-1.15)$ & $<0.001$ \\
\hline Targeted temperature management & $1.94(1.27-2.96)$ & 0.002 & & \\
\hline Use of ACE-inhibitor or ARB & $1.85(1.32-2.60)$ & $<001$ & & \\
\hline Heart failure $(<45 \%)$ & $1.51(1.03-2.19)$ & 0.033 & & \\
\hline Hypotension > 30 minutes & $2.87(2.15-3.83)$ & $<001$ & & \\
\hline Contrast used (per $10 \mathrm{ml}$ ) & $1.05(1.03-1.08)$ & $<001$ & & \\
\hline Creatinine at baseline (per 1 pnt) & $1.01(1.01-1.01)$ & $<001$ & $1.05(1.03-1.07)$ & $\dot{0} 001$ \\
\hline Use of IABP & $1.01(0.63-1.63)$ & 0.97 & & \\
\hline \multicolumn{5}{|l|}{ First rhythm (reference $=$ VF $/ V T$ ) } \\
\hline PEA & $2.25(1.16-4.39)$ & 0.017 & & \\
\hline
\end{tabular}

*If $p$-value of univariable analysis was $<0.1$, variables were entered in an backward multivariate analysis.

This figure shows the independent predictors of acute kidney injury in patients successfully resuscitated of out-of-hospital cardiac arrest. Time to return of spontaneous circulation and creatinine on baseline were independent predictors for the presence of acute kidney injury.

Abbreviations: BLS basic life support, ROSC return of spontaneous circulation, ACE-inhibitor Angiotensin-converting enzyme, ARB Angiotensin II receptor blocker, IABP intra-aortic balloon pump, PEA pulseless electrical activity, VF ventricular fibrillation, VT ventricular tachycardia. 


Asystole $2.66(1.72-4.12)<$

0.001

*If $p$-value of univariable analysis was $<0.1$, variables were entered in an backward multivariate analysis.

This figure shows the independent predictors of acute kidney injury in patients successfully resuscitated of out-of-hospital cardiac arrest. Time to return of spontaneous circulation and creatinine on baseline were independent predictors for the presence of acute kidney injury.

Abbreviations: BLS basic life support, ROSC return of spontaneous circulation, ACE-inhibitor Angiotensin-converting enzyme, ARB Angiotensin II receptor blocker, IABP intra-aortic balloon pump, PEA pulseless electrical activity, VF ventricular fibrillation, VT ventricular tachycardia.

\section{Mortality}

Since only patients surviving beyond $48 \mathrm{~h}$ were included in the study, survival until discharge was relatively high at $67.2 \%$ and did not differ between the groups, neither after propensity score matching (Table 2, Supplemental Table 2). In patients with AKI stage 3, survival until discharge and one year was lower at $43.1 \%$, respectively $36.7 \%$. Of the patients treated with RRT $50.0 \%$ survived until discharge and $46.3 \%$ were still alive after one year.

\section{Discussion}

\section{Key findings}

We have investigated the occurrence and severity of AKI in OHCA patients with early compared with deferred coronary angiography. This study did not show a higher incidence or grade of AKI in patients undergoing early angiography after OHCA. These findings suggest that coronary angiography can be performed safely either early or delayed in patients after OHCA with regard to the development of AKI. This outcome is an important addition to the results of the randomized COACT trial, which showed a similar survival for immediate and delayed angiography in OHCA patients without STEMI and also showed no difference in AKI between groups(16). Also, the present data are in line with findings from smaller retrospective cohort studies(15-18).

The reported incidence of $\mathrm{AKI}$ after cardiac arrest is up to $80 \%$ and depends on population and definition criteria(19). The incidence of AKI of $17.4 \%$ in our population is in line with previous results(15). Baseline risk factors for $\mathrm{AKI}$, such as older age and chronic kidney disease, that were found more frequently in patients with deferred angiography, might have contributed to the decision for deferral. Patients in the early angiography group more frequently had a shockable rhythm and subsequently ST-elevation on the electrocardiogram, while patients with deferred angiography were more frequently comatose. During hospitalization, intra-aortic balloon pumps were used more frequently in the early angiography group compared to the deferred angiography group. This may reflect differences in cardiovascular performance between the groups, although the use of inotropics or vasopressors did not differ. Other baseline patient 
characteristics were balanced between the groups. Furthermore, in a patient-matched analysis no higher incidence of AKI was found in the early angiography group.

Previous, smaller studies focusing on the association between timing of coronary angiography and AKI found no difference between early or delayed angiography $(15,17,18)$. With additional patient matching we accordingly did not find a higher incidence of AKI with early angiography; we even found a trend towards a higher incidence of AKI in the deferred angiography group. Considering that early angiography does not seem to aggravate the development of AKI, this may support treating physicians to choose either early or delayed coronary angiography. Remarkably, patients without angiography developed more AKI than patients that did undergo angiography. This can be explained by the fact that in patients with an overall worse condition, angiography is more often delayed. This group was older and had more comorbidities. However, mortality in the delayed angiography group was not higher than in the early angiography group.

We observed an association between the development of severe AKI after OHCA and increased mortality, which is in agreement with previous reports $(2,5,20-24)$. Patients who developed AKI more frequently had hypotension and treatment with an inotropic or vasopressor. The optimal balance between level of perfusion and vasoactive support with regard to renal function after cardiac arrest is unknown. On the one hand, increasing mean arterial pressure improves renal function in OHCA patients, but on the other hand higher level of vasoactive support may increase the incidence of AKI(25). This aspect of clinical management after cardiac arrest must be studied in future research. Targeted temperature management was used as much in the early as in the deferred angiography group, however, patients who developed AKI were more frequently treated with targeted temperature management than patients without AKI. In a substudy of the TTM trial no difference in the incidence of AKI was found between temperature management at $33^{\circ} \mathrm{C}$ or $36^{\circ} \mathrm{C}$ degrees(24). Patients who received targeted temperature management in our study may be in a worse clinical condition. Intended targeted temperature management may be a factor in the timing of coronary angiography, as in the COACT trial patients undergoing immediate angiography reached target temperature later than the delayed angiography group(16). Although the optimal strategy for targeted temperature management is still unclear $(26,27)$, potential benefit from early cooling may be a reason to postpone angiography in comatose OHCA patients without STEMI.

Patients who developed AKI had more unfavorable characteristics and arrest factors. In accordance with other studies, early coronary angiography and amount of contrast were not associated with the development of $\operatorname{AKI}(15,24)$. Only a higher baseline creatinine level and prolonged time to ROSC were independent predictors for AKI. The latter may reflect the intensity of ischemia-reperfusion injury after OHCA, of which the association with AKI has been noted in several studies $(5,20,22,24)$. Also increased creatinine on admission has been associated with development of $\operatorname{AKI}(5,19,22,24)$.

One might question whether modern iodinated contrast media are nephrotoxic at all. Several studies concluded that early intervention is not harmful with regard to $\operatorname{AKI}(16-18,20,28)$. A meta-analysis of three matched cohort studies suggested that no association between $\mathrm{AKI}$ and iodinated contrast 
exposure in critically ill patients exists at all $(15,29)$. lodinated contrast is thought to cause acute tubular necrosis through hypoxia from renal vasoconstriction and by direct cytotoxic effects within the nephron(30-32). Oxidative free radicals have been presumed to cause direct endothelial dysfunction during ischemia/reperfusion, such as after cardiac arrest $(33,34)$. Although nephrotoxicity from iodinated contrast has been well established, little is known about the pathophysiology of AKI after cardiac arrest. Furthermore, according to a meta-analysis of 52 studies, renal function does not substantially change after renal denervation with the use of contrast agents as a treatment to lower blood pressure(35).

The aim of this study was to investigate the effects of early angiography in a condition in which the renal system is already in distress after discontinuation of the circulation. The absence of augmented renal injury in this setting can be a contribution to management of patients after OHCA without STEMI, especially in the light of the newest international guidelines(36). At present, delayed as opposed to immediate angiography is recommended to be considered in OHCA patients without ST-elevation. In the decision process when to perform angiography, the lack of increased AKI incidence permits both strategies. So decision-making regarding management of OHCA patients should be individualized according to clinical status as well as to logistical circumstances.

\section{Limitations}

To the best of our knowledge, this study is the first multicenter retrospective study to evaluate the association between timing of coronary angiography and AKI in a sizeable patient cohort. Nevertheless, several limitations of our study should be noted. First, causality of the results is difficult to determine and therefore the results should be interpreted with caution. Second, data on pre-admission renal function were not available. The use of the first serum creatinine values on arrival might have underestimated prior renal function, resulting in a lower AKI incidence. However, we note that it may take $24-36 \mathrm{~h}$ for serum creatinine to rise after a definite renal insult(37). Therefore, it is likely that the creatinine concentrations measured rapidly after OHCA are reasonably representative of pre-existing renal function. Third, we cannot exclude that performance of early angiography was influenced by a history of chronic kidney disease and creatinine level upon admission, as chronic kidney disease was less frequently present in the early angiography group and baseline creatinine was lower. Finally, exclusion of patients who died within two days may have produced an unknown bias.

\section{Conclusions}

Even though the incidence of AKI in OHCA patients was substantial in this large cohort study, we found that early angiography had an equal AKI incidence as a delayed or no angiography strategy. AKI incidence was even higher in the deferred angiography group, both before and after propensity score matching. We did not find an effect of coronary angiography on renal function when adjusted for other risk factors for AKI after OHCA. The present results implicate that it is safe to perform early coronary angiography with respect to the risk of developing AKI after OHCA. 


\section{Abbreviations}

AKI: Acute kidney injury

AKIN: Acute Kidney Injury Network

Cl: Confidence interval

CPR: Cardiopulmonary resuscitation

CRP: C-reactive protein

IQR: Interquartile range

OHCA: Out-of-hospital cardiac arrest

PCl: Percutaneous coronary intervention

ROSC: Return of spontaneous circulation

STEMI: ST-segment elevation myocardial infarction

VT/VF: Ventricular tachycaradia/ventricular fibrillation

\section{Declarations}

\section{Ethics approval and consent to participate}

The study protocol was approved by the IRB of the VU University Medical Center and ethics approval was obtained by the medical ethics committee of the VU University Medical Center, Amsterdam, the Netherlands with approval number 2017.398. Informed consent was waived, as it was not achievable to obtain this from all patients of the large retrospective study cohort.

\section{Consent for publication}

The medical ethics committee approved that informed consent was waived, as it was not achievable to obtain this from all patients of the large retrospective study cohort. All authors consented for publication of the study.

\section{Availability of data and materials}

The datasets used during the current study are available from the corresponding author on reasonable request.

\section{Competing interests}


Prof. dr. van Royen reports research grants from AstraZeneca, Abbott, Philips, Biotronik and a honorarium from Medtronic. Dr. Lemkes reports grants from Biotronik and Astrazeneca, during the conduct of the study. All other authors declare no competing interests with regards to the study.

\section{Funding}

This work was supported by unrestricted research grants from the Netherlands Heart Institute, Biotronik and AstraZeneca.

\section{Authors' contributions}

GNJ conceived and designed the study, performed the acquisition, interpretation of data and drafted the manuscript. JD contributed to the acquisition. JSL contributed to the study design and acquisition. EMS contributed to the study design, performed the statistical analysis, interpretation of data and manuscript review. DJ performed the acquisition and contributed to drafting the manuscript. CAU contributed to the acquisition, LSDJ contributed to the acquisition, TACMH contributed to the acquisition and manuscript review, VAWMU contributed to the acquisition and manuscript review, FRH contributed to the acquisition and manuscript review, $A B$ contributed to the acquisition and manuscript review, JN contributed to the acquisition and manuscript review, JB contributed to the acquisition and manuscript review, PMV contributed to the statistical analysis and manuscript review, PWGE contributed to the acquisition and manuscript review, NR designed the study, performed the acquisition and manuscript review. They all agree to be accountable for all aspects of the work in ensuring that questions related to the accuracy or integrity of any part of the work are appropriately investigated and resolved. All authors read and approved the final manuscript.

\section{Acknowledgements}

Not applicable

\section{References}

1. Sasson C, Rogers MA, Dahl J, Kellermann AL. Predictors of survival from out-of-hospital cardiac arrest: a systematic review and meta-analysis. Circ Cardiovasc Qual Outcomes. 2010;3(1).

2. Yanta J, Guyette FX, Doshi AA, Callaway CW, Rittenberger JC. Post Cardiac Arrest S. Renal dysfunction is common following resuscitation from out-of-hospital cardiac arrest. Resuscitation. 2013;84(10).

3. Levy EM, Viscoli CM, Horwitz RI. The effect of acute renal failure on mortality. A cohort analysis. JAMA. 1996;275:19.

4. Sandroni C, Dell'anna AM, Tujjar O, Geri G, Cariou A, Taccone FS. Acute kidney injury after cardiac arrest: a systematic review and meta-analysis of clinical studies. Minerva Anestesiol. 2016;82(9). 
5. Tujjar O, Mineo G, Dell'Anna A, Poyatos-Robles B, Donadello K, Scolletta S, et al. Acute kidney injury after cardiac arrest. Crit Care. 2015;19:169.

6. Barrett BJ, Parfrey PS. Clinical practice. Preventing nephropathy induced by contrast medium. N Engl J Med. 2006;354(4).

7. Wong PC, Li Z, Guo J, Zhang A. Pathophysiology of contrast-induced nephropathy. Int J Cardiol. 2012;158(2).

8. Mehran R, Aymong ED, Nikolsky E, Lasic Z, lakovou I, Fahy M, et al. A simple risk score for prediction of contrast-induced nephropathy after percutaneous coronary intervention: development and initial validation. J Am Coll Cardiol. 2004;44(7).

9. Azzalini L, Candilio L, McCullough PA, Colombo A. Current Risk of Contrast-Induced Acute Kidney Injury After Coronary Angiography and Intervention: A Reappraisal of the Literature. Can J Cardiol. 2017;33(10).

10. Ibanez B, James S, Agewall S, Antunes MJ, Bucciarelli-Ducci C, Bueno H, et al. 2017 ESC Guidelines for the management of acute myocardial infarction in patients presenting with ST-segment elevation: The Task Force for the management of acute myocardial infarction in patients presenting with STsegment elevation of the European Society of Cardiology (ESC). Eur Heart J. 2018;39(2).

11. O'Gara PT, Kushner FG, Ascheim DD, Casey DE Jr, Chung MK, de Lemos JA, et al. 2013 ACCF/AHA guideline for the management of ST-elevation myocardial infarction: a report of the American College of Cardiology Foundation/American Heart Association Task Force on Practice Guidelines. J Am Coll Cardiol. 2013;61(4).

12. Nolan JP, Sandroni C, Bottiger BW, Cariou A, Cronberg T, Friberg H, et al. European Resuscitation Council and European Society of Intensive Care Medicine Guidelines 2021: Post-resuscitation care. Resuscitation. 2021;161.

13. Welsford M, Nikolaou NI, Beygui F, Bossaert L, Ghaemmaghami C, Nonogi H, et al. Part 5: Acute Coronary Syndromes: 2015 International Consensus on Cardiopulmonary Resuscitation and Emergency Cardiovascular Care Science With Treatment Recommendations. Circulation. 2015;132(16 Suppl 1).

14. Mehta RL, Kellum JA, Shah SV, Molitoris BA, Ronco C, Warnock DG, et al. Acute Kidney Injury Network: report of an initiative to improve outcomes in acute kidney injury. Crit Care. 2007;11(2).

15. Petek BJ, Bravo PE, Kim F, de Boer IH, Kudenchuk PJ, Shuman WP, et al. Incidence and Risk Factors for Postcontrast Acute Kidney Injury in Survivors of Sudden Cardiac Arrest. Ann Emerg Med. 2016;67(4).

16. Lemkes JS, Janssens GN, van der Hoeven NW, Jewbali LSD, Dubois EA, Meuwissen M, et al. Coronary Angiography after Cardiac Arrest without ST-Segment Elevation. N Engl J Med. 2019;380(15).

17. Christ M, Auenmuller KI, Amirie S, Brand M, Sasko BM, Trappe HJ. [Acute kidney injury and renal replacement therapy in victims from out-of-hospital cardiac arrest with administration of contrast agent]. Herzschrittmacherther Elektrophysiol. 2016;27(1). 
18. Noc M, Fajadet J, Lassen JF, Kala P, MacCarthy P, Olivecrona GK, et al. Invasive coronary treatment strategies for out-of-hospital cardiac arrest: a consensus statement from the European association for percutaneous cardiovascular interventions (EAPCI)/stent for life (SFL) groups. Eurolntervention. 2014;10(1).

19. Kim YW, Cha KC, Cha YS, Kim OH, Jung WJ, Kim TH, et al. Shock duration after resuscitation is associated with occurrence of post-cardiac arrest acute kidney injury. J Korean Med Sci. 2015;30(6).

20. Chua HR, Glassford N, Bellomo R. Acute kidney injury after cardiac arrest. Resuscitation. 2012;83(6).

21. Domanovits $H$, Schillinger M, Mullner M, Thoennissen J, Sterz F, Zeiner $A$, et al. Acute renal failure after successful cardiopulmonary resuscitation. Intensive Care Med. 2001;27(7).

22. Geri G, Guillemet L, Dumas F, Charpentier J, Antona M, Lemiale V, et al. Acute kidney injury after outof-hospital cardiac arrest: risk factors and prognosis in a large cohort. Intensive Care Med. 2015;41(7).

23. Hasper D, von Haehling S, Storm C, Jorres A, Schefold JC. Changes in serum creatinine in the first 24 hours after cardiac arrest indicate prognosis: an observational cohort study. Crit Care. 2009;13(5).

24. Rundgren M, Ullen S, Morgan MPG, Glover G, Cranshaw J, Al-Subaie N, et al. Renal function after outof-hospital cardiac arrest; the influence of temperature management and coronary angiography, a post hoc study of the target temperature management trial. Crit Care. 2019;23(1).

25. Grand J, Hassager $C$, Winther-Jensen $M$, Rundgren $M$, Friberg $H, H o r n ~ J$, et al. Mean arterial pressure during targeted temperature management and renal function after out-of-hospital cardiac arrest. J Crit Care. 2019;50.

26. Bernard SA, Smith K, Cameron P, Masci K, Taylor DM, Cooper DJ, et al. Induction of therapeutic hypothermia by paramedics after resuscitation from out-of-hospital ventricular fibrillation cardiac arrest: a randomized controlled trial. Circulation. 2010;122(7).

27. Kim F, Nichol G, Maynard C, Hallstrom A, Kudenchuk PJ, Rea T, et al. Effect of prehospital induction of mild hypothermia on survival and neurological status among adults with cardiac arrest: a randomized clinical trial. JAMA. 2014;311(1).

28. Joannidis M, Druml W, Forni LG, Groeneveld ABJ, Honore PM, Hoste E, et al. Prevention of acute kidney injury and protection of renal function in the intensive care unit: update 2017: Expert opinion of the Working Group on Prevention, AKI section, European Society of Intensive Care Medicine. Intensive Care Med. 2017;43(6).

29. Ehrmann S, Quartin A, Hobbs BP, Robert-Edan V, Cely C, Bell C, et al. Contrast-associated acute kidney injury in the critically ill: systematic review and Bayesian meta-analysis. Intensive Care Med. 2017;43(6).

30. Brezis M, Rosen S. Hypoxia of the renal medulla-its implications for disease. N Engl J Med. 1995;332(10).

31. Heyman SN, Rosenberger C, Rosen S. Regional alterations in renal haemodynamics and oxygenation: a role in contrast medium-induced nephropathy. Nephrol Dial Transplant. 2005;20 Suppl 1. 
32. Persson PB, Hansell P, Liss P. Pathophysiology of contrast medium-induced nephropathy. Kidney Int. 2005;68(1).

33. Tsao PS, Aoki N, Lefer DJ, Johnson G 3rd, Lefer AM. Time course of endothelial dysfunction and myocardial injury during myocardial ischemia and reperfusion in the cat. Circulation. 1990;82(4).

34. Yoshioka T, Fogo A, Beckman JK. Reduced activity of antioxidant enzymes underlies contrast mediainduced renal injury in volume depletion. Kidney Int. 1992;41(4).

35. Sanders MF, Reitsma JB, Morpey M, Gremmels H, Bots ML, Pisano A, et al. Renal safety of catheterbased renal denervation: systematic review and meta-analysis. Nephrol Dial Transplant. 2017;32(9).

36. Collet JP, Thiele H, Barbato E, Barthelemy O, Bauersachs J, Bhatt DL, et al. 2020 ESC Guidelines for the management of acute coronary syndromes in patients presenting without persistent ST-segment elevation. Eur Heart J. 2020.

37. Ostermann M, Joannidis M. Acute kidney injury 2016: diagnosis and diagnostic workup. Crit Care. 2016;20(1).

\section{Figures}

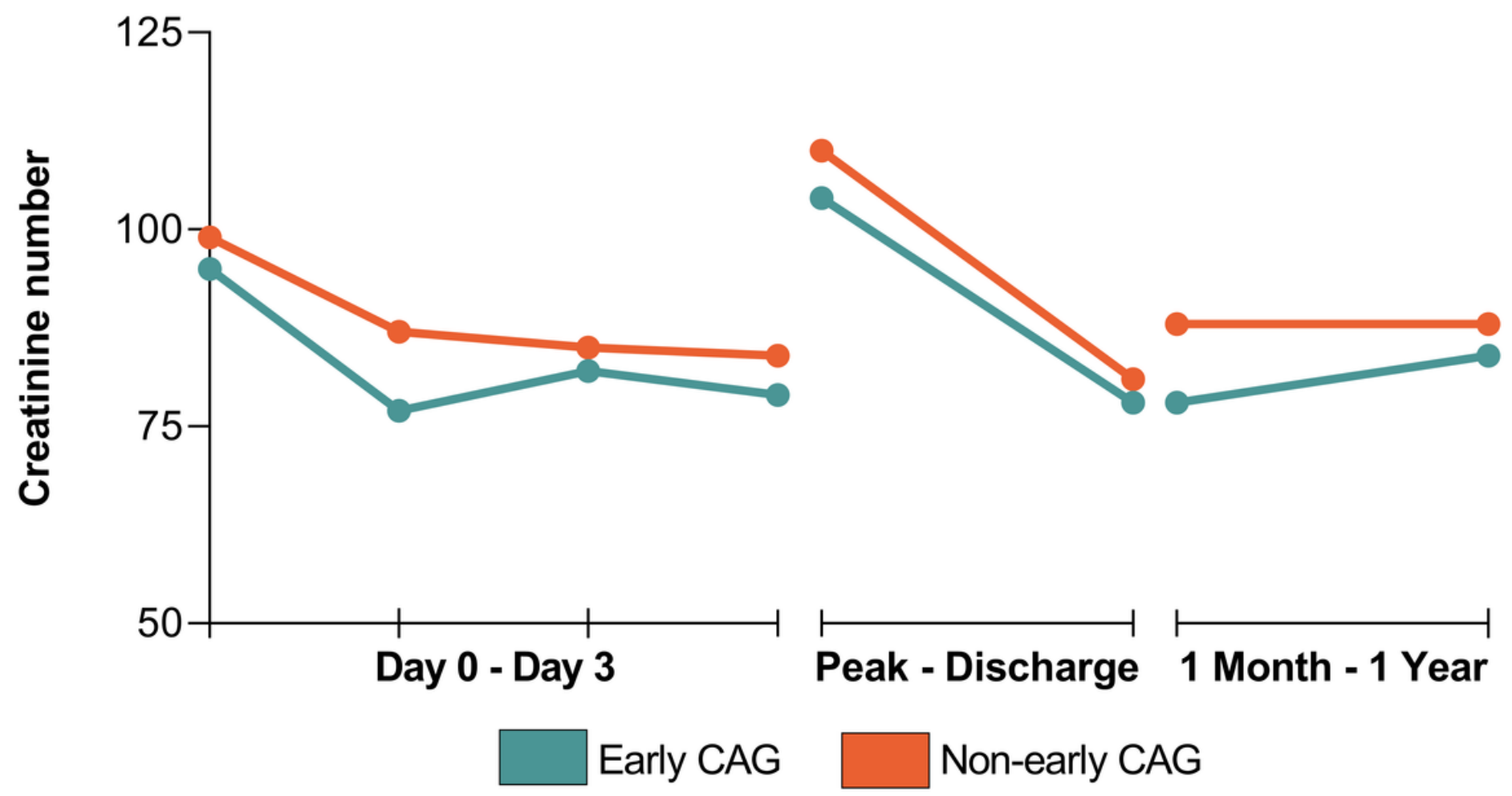

Figure 1

Creatinine levels CAG denotes coronary angiography. 


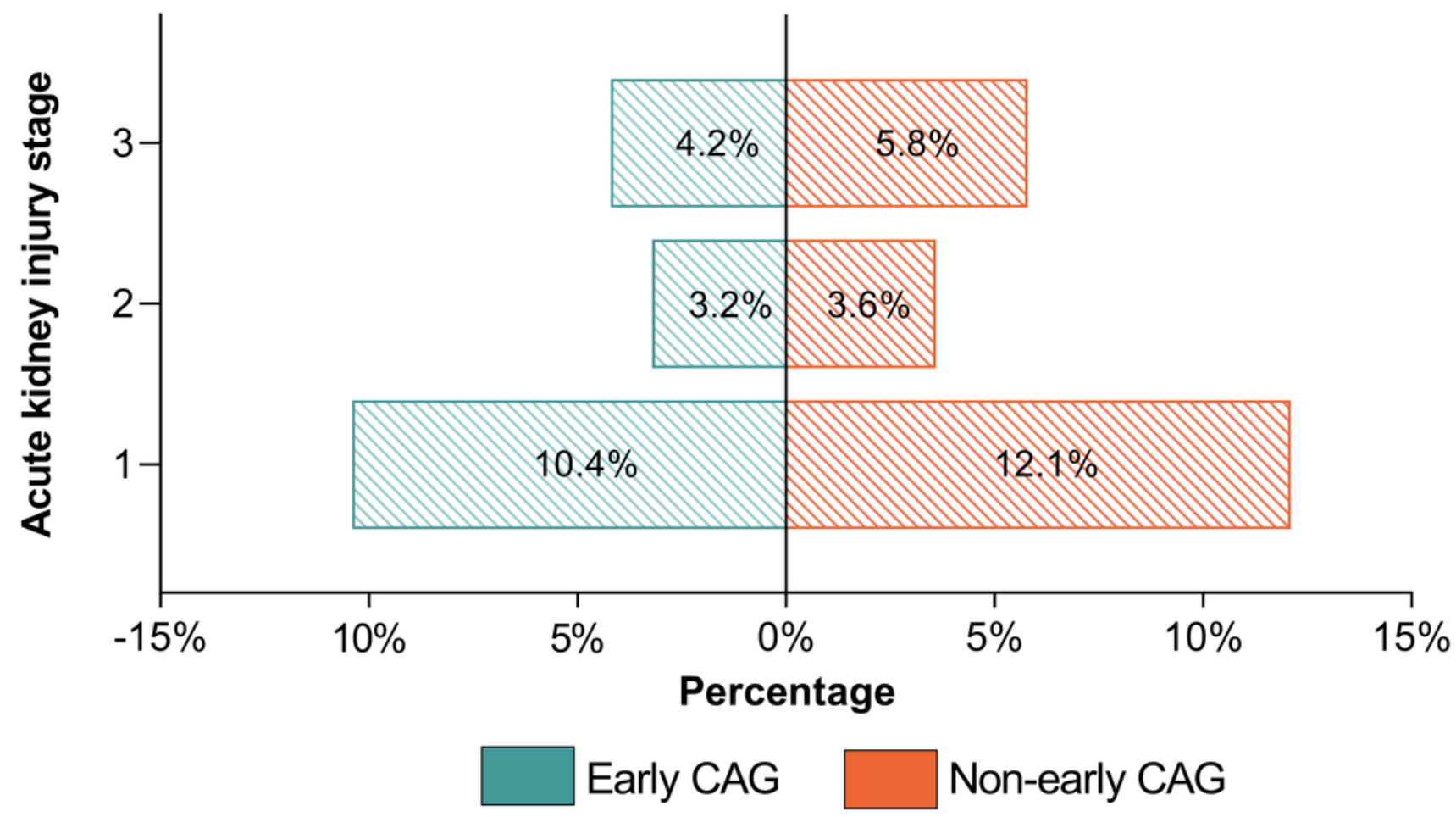

Figure 2

Incidence of acute kidney injury On the left side in the graph the early angiography group is displayed in blue, on the right side the non-early angiography group is displayed in red.

\section{Supplementary Files}

This is a list of supplementary files associated with this preprint. Click to download.

- GraphicalabstractimageCC821.jpg

- SupplementAKlafterOHCA821.docx 